Research Article

\title{
Dynamic Response of Steel Box Girder under Internal Blast Loading
}

\author{
Shujian Yao $\mathbb{D}^{1,2}$ Nan Zhao, ${ }^{1,3}$ Zhigang Jiang, ${ }^{4}$ Duo Zhang, ${ }^{2}$ and Fangyun Lu $^{2}$ \\ ${ }^{1}$ School of Traffic and Transportation Engineering, Central South University, Changsha, Hunan 410075, China \\ ${ }^{2}$ College of Science, National University of Defense Technology, Changsha, Hunan 410073, China \\ ${ }^{3}$ PowerChina, Zhongnan Engineering Corporation Limited, Changsha, Hunan 410072, China \\ ${ }^{4}$ College of Basic Education, National University of Defense Technology, Changsha, Hunan 410072, China
}

Correspondence should be addressed to Shujian Yao; yaoshujian@gmail.com

Received 16 August 2017; Revised 6 November 2017; Accepted 5 December 2017; Published 29 March 2018

Academic Editor: Michel Arrigoni

Copyright (c) 2018 Shujian Yao et al. This is an open access article distributed under the Creative Commons Attribution License, which permits unrestricted use, distribution, and reproduction in any medium, provided the original work is properly cited.

\begin{abstract}
This paper aims at investigating the dynamic response of the steel box girder under internal blast loads through experiments and numerical study. Two blast experiments of steel box models under internal explosion were conducted, and then, the numerical methods are introduced and validated. The dynamic response process and propagation of the internal shock wave of a steel box girder under internal blast loading were investigated. The results show that the propagation of the internal shock wave is very complicated. A multi-impact effect is observed since the shock waves are restricted by the box. In addition, the failure modes and the influence of blast position as well as explosive mass were discussed. The holistic failure mode is observed as local failure, and there are two failure modes for the steel box girder's components, large plastic deformation and rupture. The damage features are closely related to the explosive position, and the enhanced shock wave in the corner of the girder will cause severe damage. With the increasing TNT mass, the crack diameter and the deformation degree are all increased. The longitudinal stiffeners restrict the damage to develop in the transverse direction while increase the crack diameter along the stiffener direction.
\end{abstract}

\section{Introduction}

Since the 9-11 attacks by terrorists, there has been increasing public concern about the threat of bomb attacks on infrastructure such as bridges and tunnels as well as buildings. Major and monumental bridges might be targeted by terrorists because collapse of these structures can cause economic disaster, a large number of casualties, and great public panic. Therefore, protection of major bridges against blast load has been attached great importance by the international bridge community [1-3].

Many scholars studied the responses of concrete bridge structural components under blast loadings by using simplified theory method, such as Timoshenko beam theory [4] and analysis of equivalent single degree of freedom (SDOF) system [5-8]. These simplified methods are very efficient, but it is difficult to give reliable predictions of localized damages. However, with the advancement in computer technology and computational mechanics techniques, the numerical simulation method had been widely used in investigations of blast effect on structures, and these simulations are proved yielding to reliable structural response predic-tions $[9,10]$.

Large span cable-supported bridge is under great risk of terrorist bomb attacks; many scholars processed numbers of numerical simulation studies on it. Through numerical simulations, Deng et al. [11] analyzed the impact damage of continuous steel truss single tower cable-stayed bridge under blast loads, and Son [12] and Son and Lee [13] analyzed the explosion impact response of the deck and the tower structure of cable-supported bridge. Tang and Hao [14] and Hao and Tang [15] studied the localized destruction of the bridge towers, piers, and deck structure as well as the overall collapse of a long span cable-stayed bridge under car bomb blast loading through numerical simulations with the nonlinear finite element software LS-DYNA. 
Steel box girder has many advantages, such as much lighter, easy shaped, and can save construction time, and is now become the most common type of the main beam of large span cable-supported bridge. The response of orthotropic steel decks and steel box girders under terror blast loading was investigated with ANSYS/LS-DYNA by Jiang et al. [16], and the breach process and failure mechanism of the deck had been analyzed deeply.

Researches in [17-20] had shown that interaction mechanism of internal blast is more complex, and the destructive effect is more strongly than free air explosion, so the study of internal explosion of steel box girder is necessary and imperative.

The ALE fluid-structure coupling algorithm can consider the influence of the structure's response to the propagation of shock wave and is approved of accuracy [21-24]. In the current study, the numerical methods are validated through comparison of experimental and numerical results. Then, finite element models of the steel box girder are established and numerical simulations are carried out with ANSYS/LSDYNA using the ALE algorithm. The dynamic response process and propagation of internal shock wave inside the steel box girder are analyzed. The failure mode and the influence of blast position as well as explosive mass are also discussed.

The results obtained in this study give information for owners of similar type of structures on the probable responses when subjected to internal blast loads and can assist engineers to choose the most effective retrofit measures to bring in better resistance against internal blast loads.

\section{Validation of the Numerical Method}

2.1. Experimental Setup. To validate the effectiveness of the numerical method for the box-shaped steel structure under internal blast, two steel box models with the same dimension were designed and manufactured to conduct internal blast experiments. The box model is made up of $2 \mathrm{~mm}$ thickness Q235 mild steel plates with Young's modulus of $200 \mathrm{GPa}$. The yield strength and ultimate strength of Q235 steel are $370 \mathrm{MPa}$ and $485 \mathrm{MPa}$, respectively, which are obtained through tensile test with MTS.

The steel box specimen is shown in Figure 1. The side length of all side plates is $300 \mathrm{~mm}$, and an extra length of $60 \mathrm{~mm}$ is welded to every box side plate for the purpose of simulating the constraint condition. A hole is reserved in the center of the top plate for the purpose of placing the explosive. The final dimension of the specimens is $420 \mathrm{~mm} \times 420 \mathrm{~mm} \times$ $420 \mathrm{~mm}$. Two different explosive masses of $12.8 \mathrm{~g}$ and $40.2 \mathrm{~g}$ are selected with the purpose of examining different damage degrees.

2.2. Numerical Model. Finite element models with the same dimension of experiments were built by ANSYS/LS-DYNA; the box model is shown in Figure 2(a). The explosive is defined in the central region of air as shown in Figure 2(b). The explosive and air are meshed with the eight-node element SOLID164, while the box is meshed with four-node

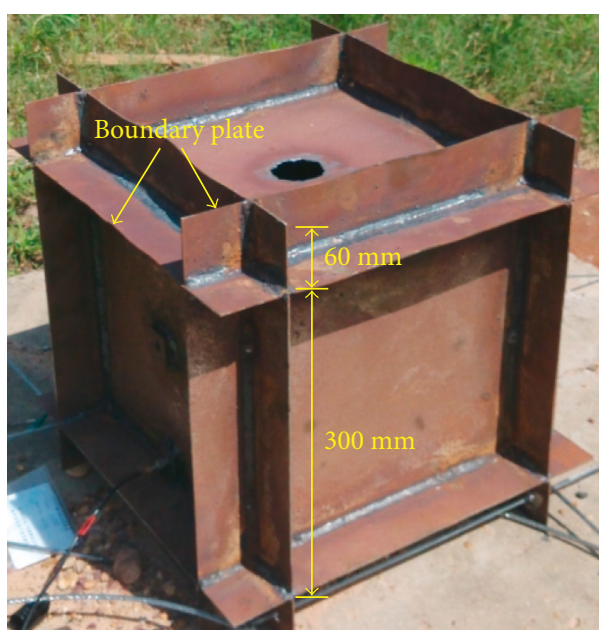

Figure 1: Steel box specimen.

element SHELL163. The fluid-structure interaction algorithm is adopted to model the impacts of blast wave to structure. The mesh size of structure and air are $5 \mathrm{~mm}$ and $4 \mathrm{~mm}$, respectively. The total element numbers for the shell and solid are 42,820 and 1520,875, respectively.

In these numerical models, ${ }^{*} \mathrm{MAT}$ _HIGH EXPLOSIVE_BURN is used for high explosives (TNT), and the JWL equation of state is adopted to model the pressure generated from blast [25]. The Johnson-Cook material model together with the Gruneisen state equation is used to model the dynamic behavior of the steel box $[26,27]$.

\subsection{Comparisons of Numerical and Experimental Results. Figure} 3 shows the comparison of damage features obtained from both blast tests and numerical simulations. Outward bulging of the whole plate is observed in all sides of all tests, and inplane buckling produces in the central area of the boundary plates. These damage features are all observed in numerical results as shown in the right-side pictures of Figure 3 which indicate that the numerical model can simulate the damage features well.

The side plate center deflection-time curves obtained through numerical simulations of both tests are shown in Figure 4. The ultimate plate center deflections of experiments were measured by using an electronic digital display depth caliper, and the ultimate deflections for $12.8 \mathrm{~g}$ and $40.2 \mathrm{~g}$ TNT tests are $14.9 \mathrm{~mm}$ and $34.4 \mathrm{~mm}$, respectively. The ultimate deflections of simulation results cannot be obtained directly since the calculating time is limited. However, the deflection data after the first extreme value present a phenomenon of oscillation around a specific value as shown in Figure 4. Hence, the ultimate deflections could be estimated through analyzing the corresponding deflection-time curves. The estimated ultimate deflections for $12.8 \mathrm{~g}$ and $40.2 \mathrm{~g}$ TNT simulations are $15.5 \mathrm{~mm}$ and $35.5 \mathrm{~mm}$, respectively. It shows that the maximum error of $4 \%$ occurs in the FEM calculated to caliper measured of experiments.

The above analyses indicate that the deformation features and deflection data obtained through finite element 


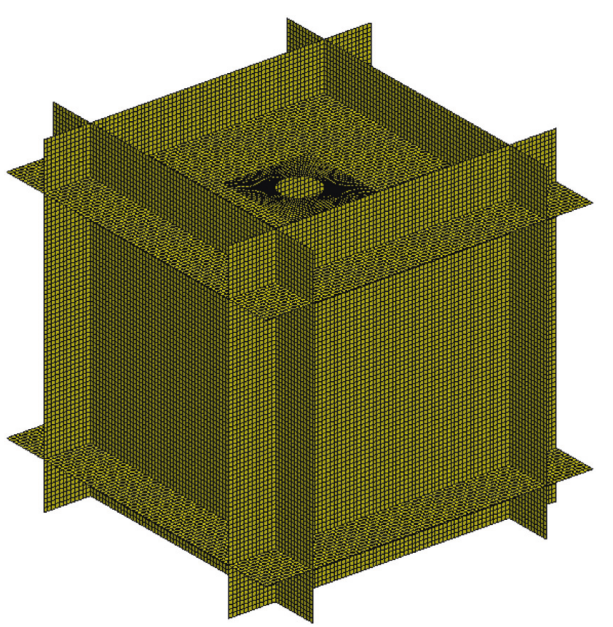

(a)

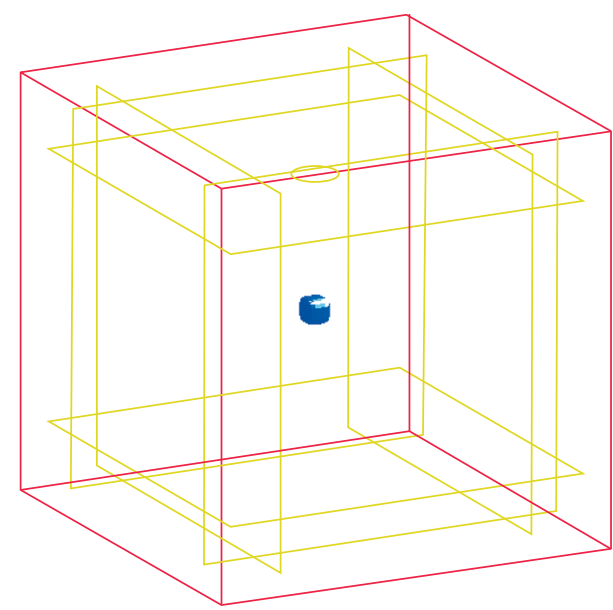

(b)

Figure 2: Finite element model. (a) Box model. (b) Air and explosive.

method are in good agreement with the experimental results, and hence the numerical method is validated.

\section{Finite Element Models of Steel Box Girder under Internal Blast Loading}

Considered the localized effect of blast load and the calculated efficiency, a segment of the steel box girder has been selected as the analytical model in this paper. Figure 5 shows the girder's cross section and four typical explosive positions; the bombs in positions 2 and 3 have only one-side contact to the soleplate, while positions 1 and 4 have two or three sides contact to soleplate and diaphragms, named multisides contact. The position 4 located next to the joint of four boxes, $1.96 \mathrm{~m}$ away from position 1 . The length of the girder segment (along the direction of bridge) is $12.0 \mathrm{~m}$; the distance of two transverse diaphragms is $4.0 \mathrm{~m}$; the thickness of the diaphragm is $12 \mathrm{~mm}$; the width of the roof (along the transverse direction of bridge) is $20.12 \mathrm{~m}$ and thickness is $14 \mathrm{~mm}$, while the bottom plate is $17 \mathrm{~m}$ and thickness is $10 \mathrm{~mm}$; the thickness of longitudinal diaphragm is $9 \mathrm{~mm}$ and $\mathrm{U}$-shaped stiffener is $6 \mathrm{~mm}[17,28]$. The calculation model is shown in Figure 6: situation of positions 1 3 is longitudinal symmetry, and a $1 / 2$ segment model is given, while position 4 is unsymmetrical, a $2 / 3$ segment model is selected which includes 3 transverse diaphragms (as shown in Figure 6(b)). 8-node solid element type (SOLID164) is used for modeling air and TNT; SHELL163 element type is selected for the steel box in these simulations. The automatic single surface contact type ( ${ }^{*}$ Contact_Automatic_Single_Surface) is defined to consider the contact and collision of different plates or fragments. The mesh size for the girder is $5 \mathrm{~cm}$, and the mesh size for air is in proportion to the explosive distance (the mesh size for the central zone of explosive position is smaller than $2 \mathrm{~cm}$ ).

With the purpose of investigating the influence of blast position and explosive mass, two sets of simulations are designed. The first set is for the blast position, in which four typical blast positions (Figure 5) are selected with an explosive mass of $23 \mathrm{~kg}$ TNT (typical suitcase bomb). The other set is for explosive mass where four different TNT masses ranging from $10 \mathrm{~kg}$ to $50 \mathrm{~kg}$ are detonated in position 2 (as shown in Figure 5).

\section{Response Process and the Propagation of Internal Shock Waves}

4.1. One-Side Contact Explosion Situation. The response process of the bomb exploded in positions 2 and 3 is similar because they both belong to the type of one-side contact which leads to serve destruction only in the TNT-concluded box while the neighboring box is less influenced. The position 2 is taken as an example to study the response process for position 2 located next to the chamber center which is more typical. In Figure 7, some pressure fringe plots at typical time are given, and the pressure unit in these plots is $\mathrm{Pa}$. Figure 8 shows the positions of 4 elements and their ID in the four corners of the right box chamber as well as their pressure-time curves.

The response progresses are as follows: $t \approx 0.14 \mathrm{~ms}$, the bottom plate has generated local large deformation; $t \approx 0.78 \mathrm{~ms}$, the shock wave has reached the roof first time; thereafter, the shock wave reflects back from the roof. When the shock wave arrives the diaphragm and longitudinal clapboard, deformation is caused immediately, and then the shock waves reflect back again to the center of the roof from both sides of the diaphragms at $t \approx 4.4 \mathrm{~ms}$ which causes a secondary impact; $t \approx 8.8 \mathrm{~ms}$, shock waves convergence occur at the four corners of the box, at which larger overpressure produces (as shown in Figure 8), and the shock waves converge in the " $>$ " shaped corner (constituted by the right-inclined web and roof) and was much more stronger which led to a severer impact on the roof (as shown in Figure 9); shock waves reach the joint of the longitudinal clapboard and bottom plate again at $\mathrm{t} \approx 16.74 \mathrm{~ms}$ causing secondary impacts (element $\mathrm{B}$ position and pressure-time curves are shown in Figure 8); after that, multiple reflections take place while the shock wave intensity gradually decreases. 

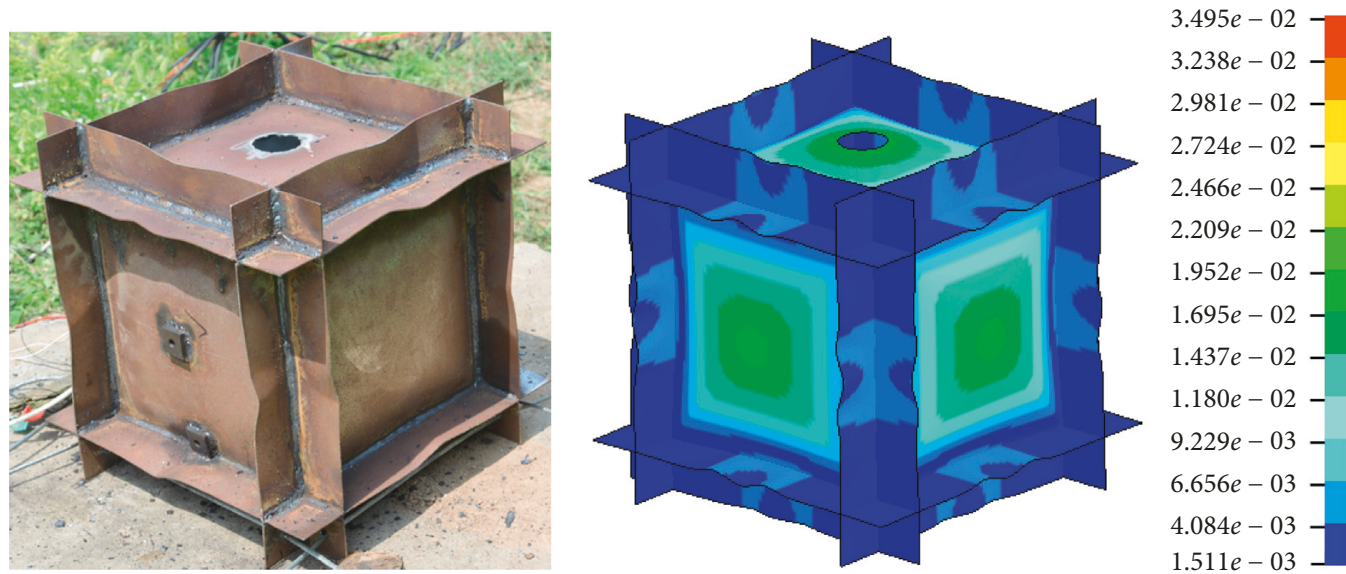

(a)
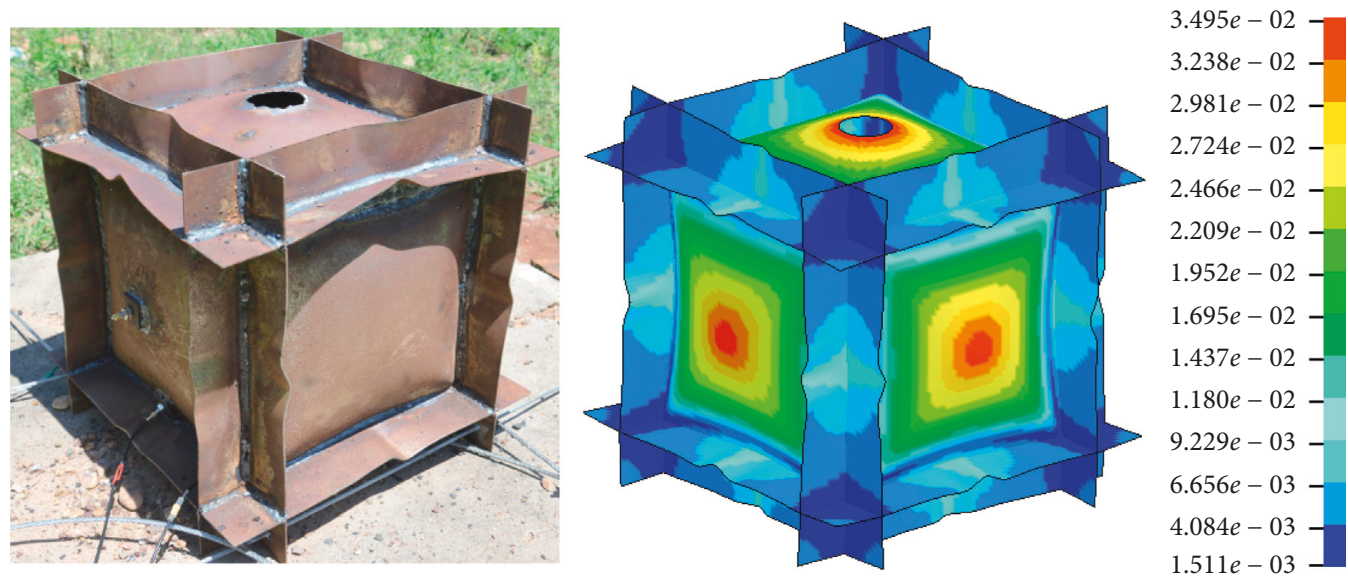

(b)

Figure 3: Deformation comparison between experimental result and numerical result (the left picture is the experimental result and the right is numerical). (a) $12.8 \mathrm{~g}$ TNT. (b) $40.2 \mathrm{~g}$ TNT.

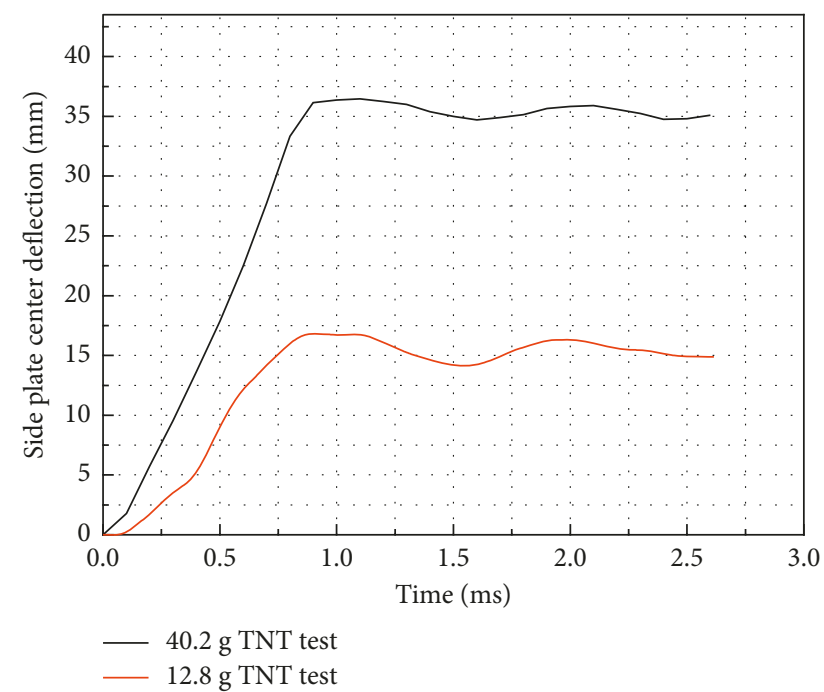

FIGURE 4: The side plate center deflection-time curves obtained through numerical simulations.
From Figure 8, elements $\mathrm{B}$ and $\mathrm{D}$ reach the first peak pressure at $t \approx 8.76 \mathrm{~ms}$, and the magnitude of unit $\mathrm{B}$ is up to $0.82 \mathrm{MPa} ; t \approx 14 \mathrm{~ms}$, unit $A$ reaches the second peak pressure $0.3 \mathrm{MPa}$, and at $t \approx 17 \mathrm{~ms}$, element $\mathrm{B}$ reaches a second peak pressure of $0.36 \mathrm{MPa}$, the second impact peak pressure can reach more than one-third of the first peak pressure, and it seems that the second impact effect cannot be neglected; and then series of reflection peak pressure were also observed though the pressure magnitude attenuated.

In Figure 9, the fringe plot of displacement and the elements' position of the deck is shown; the element of the deck (element 1218 to 23,658 ) in order from left to right is counted as A D. Figure 10 shows the deflection-time curves (positive upward) of the elements A D. From Figures 9 and 10 , the positions close to elements $\mathrm{C}$ and $\mathrm{D}$ have maximum deformation, where element $\mathrm{C}$ was under direct impact by the shock wave, while the explosive distance of element $\mathrm{D}$ is farther but located at the corner where the shock wave aggregation effect strengthened in, so big deflection of about $0.093 \mathrm{~m}$ appeared in those two areas. 


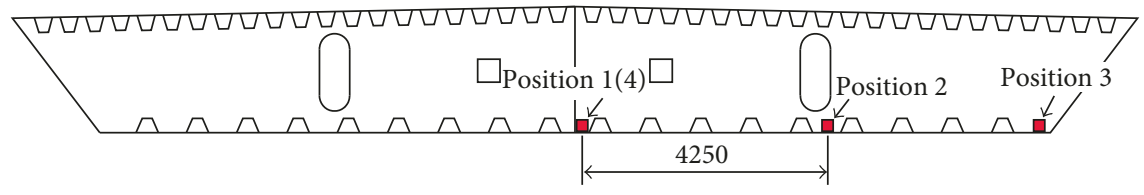

Figure 5: Cross section and explosive positions (unit: $\mathrm{mm}$ ).

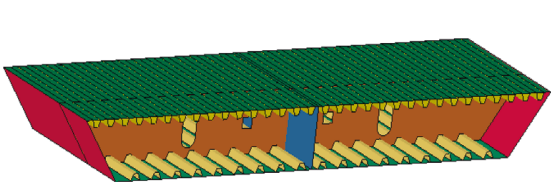

(a)

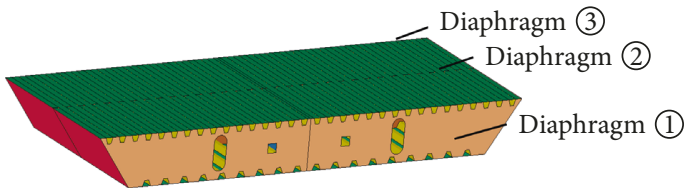

(b)

FIGURE 6: Finite element models. (a) 1/2 girder. (b) 2/3 girder.

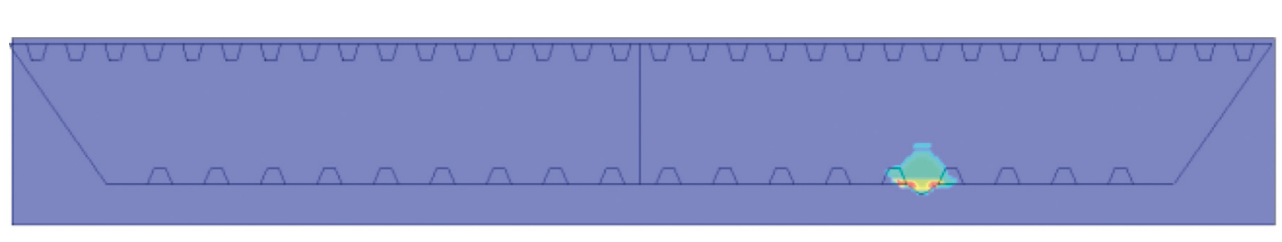

Fringe level

$5,000 e+07$

$4.167 e+07]$

$3.333 e+07$

$2.500 e+07$

$1,667 e+07$

$8,333 e+06$

$t=0.1392$

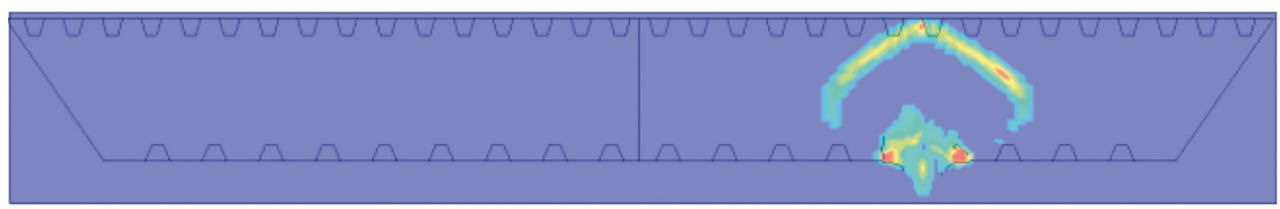

Fringe levels

$2.000 e+06$

$1.667 e+06$

$1.333 e+06$

$1.000 e+06$

$6.667 e+05$

$3.333 e+05$

$t=0.7790$

Fringe levels

$2.000 e+06$

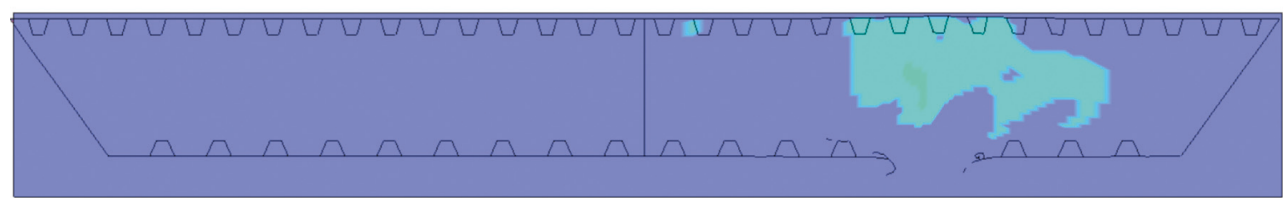

$1.667 e+06]$

$1.333 e+06$

$1.000 e+06$

$6.667 e+05$

$3.333 e+05$

$t=4.439$

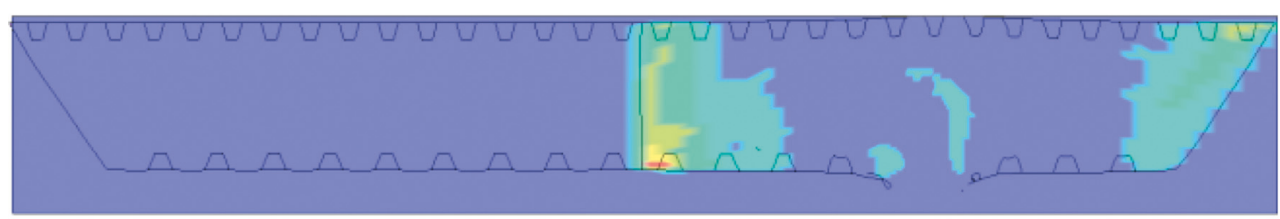

Fringe levels

$1.000 e+06$

$8.333 e+05]$

$6.667 e+05$

$5.000 e+05$

$3.333 e+05$

$1.667 e+05$

$t=8.7597$

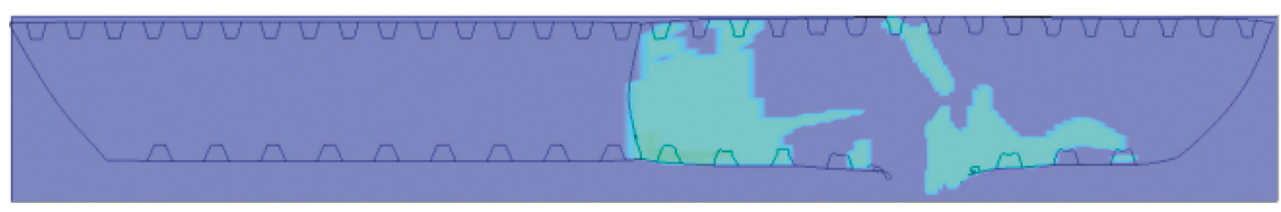

Fringe levels

$1.000 e+06$

$8.333 e+05$

$6.667 e+05$

$5.000 e+05$

$3.333 e+05$

$1.667 e+05$

$t=16.740$

Figure 7: Pressure evolutions of explosion in position 2 (middle cross section, time unit: ms)

4.2. Multiside Contact Explosion Situation. Blasts in position 1 and position 4 belong to multiside contact explosion, especially position 4 close to three plates; the blast wave was constrained seriously by 3 sides, and the adjacent four box chamber was greatly influenced. For this reason, the position 4 explosion was selected to analyze the response process and damage effects. Figure 11 shows some pressure fringe plots at typical time, and the pressure unit in these plots is $\mathrm{Pa}$.

The response processes are $t \approx 0.1 \mathrm{~ms}$, the bottom plate and longitudinal, transverse diaphragm had already produced local large deformation and cracks, and the bottom 


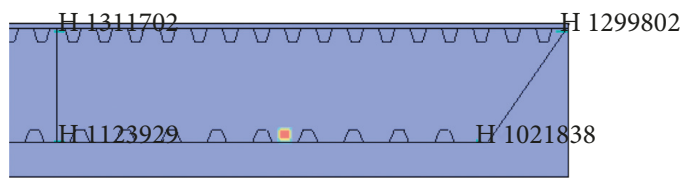

(a)

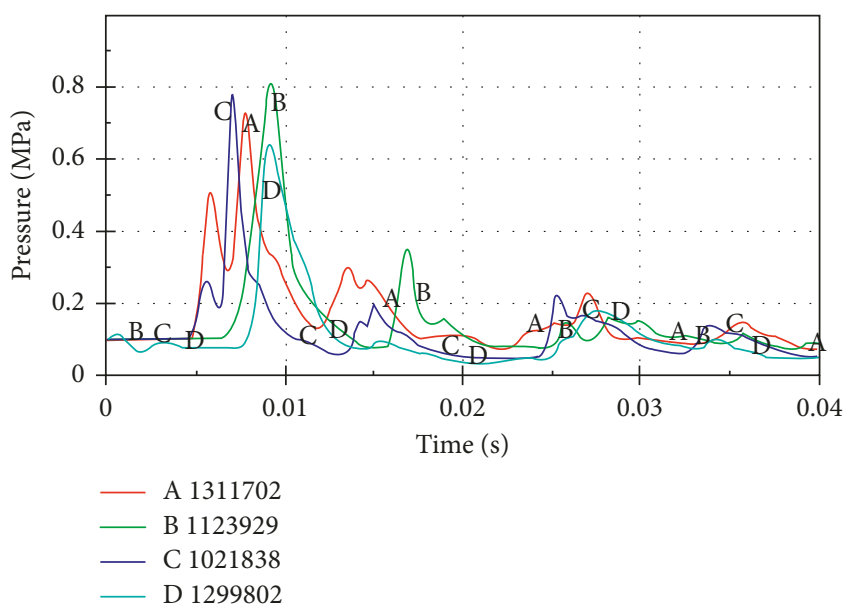

(b)

Figure 8: (a) The elements' position and (b) pressure-time curves.

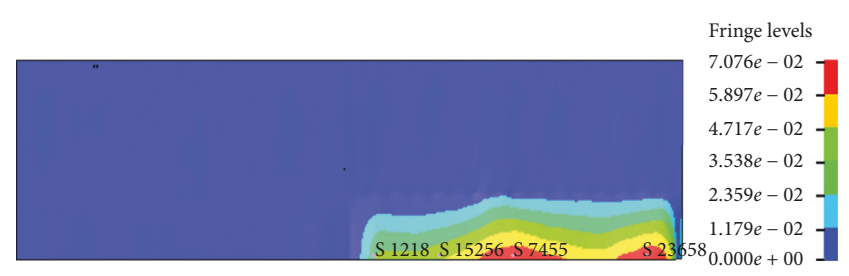

Figure 9: Fringe plot of displacement and the elements' position of the deck (top view, unit: $\mathrm{m}$ ).

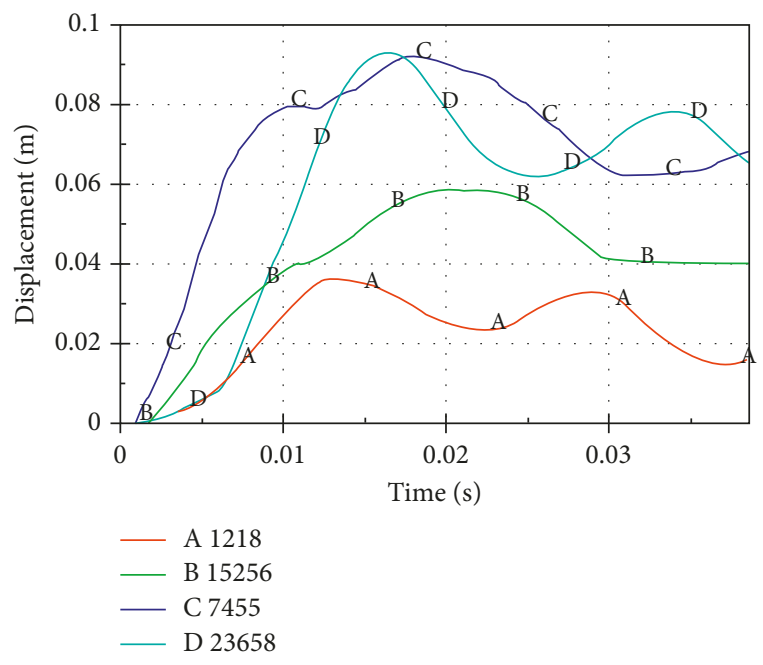

Figure 10: Deflection-time curves of the deck.

plate and diaphragm plate (2) has fragments produced; $t \approx 0.8 \mathrm{~ms}$, the shock wave reaches the roof, and the roof begins to deform; $t \approx 1.5 \mathrm{~ms}$, the shock wave reaches diaphragm plate (1); $t \approx 2.8 \mathrm{~ms}$, the shock waves are encountered in the top right-hand corner of the right-hand box chamber, and at the same time, the shock wave crosses the hole in diaphragm plate (2) and traverses the left box chamber and reaches diaphragm plate (3); $\mathrm{t} \approx 5.2 \mathrm{~ms}$, the shock waves in the left box chamber are converged in the upper-left corner; at the same time, the roof diaphragm plate (1) in the right box room has produced great deformation; $t \approx 9.8 \mathrm{~ms}$, the shock waves in the right box reflect back again and encounter at the place just below the roof and above the explosive directly; element $\mathrm{B}$ reaches the extreme values for the first time; since then, multiple reflections take place in each box chamber while the shock wave intensity rapidly reduces.

\section{Discussions}

5.1. Damage Mode Analysis. The fringe plots of final displacement of different whole models, bottom plate, and roof are given in Figures 12-14. The longitudinal and transverse diaphragms have been destroyed seriously when the bomb is exploded in position 1 and position 4; a diameter of larger than $1 \mathrm{~m}$ breaches is observed in the longitudinal diaphragm in both positions 1 and 4; the damage degree in position 2 is much lighter, which may be because of the bomb in position 2 only in contact with one side (the bottom plate), which means constraint effect is not obvious. In position 3 , the deformation of the roof is the largest, which may be caused by the impact of the shock wave converged in the top right corner. The damage degree is the most serious in position 4 as shown in Figures 13 and 14 .

The three transverse diaphragms' deformation and the final damage shape of explosion in position 4 are shown in Figures 15 and 16. The diaphragm (2) is cracked, and the crevasse size is $0.91 \mathrm{~m} \times 0.75 \mathrm{~m}$, and the diaphragms (1) and (3) undergo great deformation, and the deformation is in opposite directions, which are caused by shock waves in different chambers. The final shape of damage shows that the local failure is serious, and the tearing break phenomenon at the weld zone is obvious.

On the whole, the failure mode of the steel box girder includes two levels; one is the holistic failure mode of the steel box, and the other is the failure mode of plates. The holistic failure mode presented local failure obviously in the 


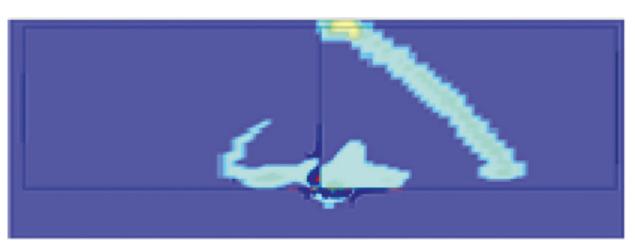

(a)

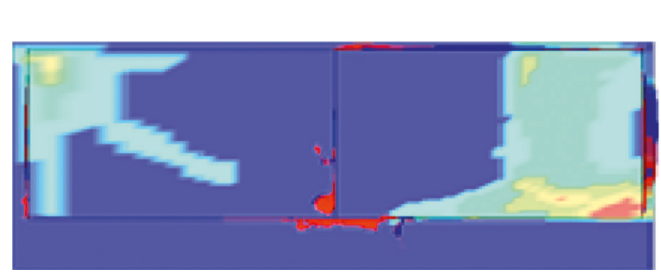

(c)

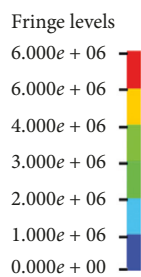

Fringe levels

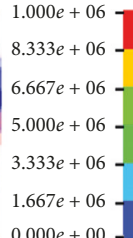

$1.667 e+06$

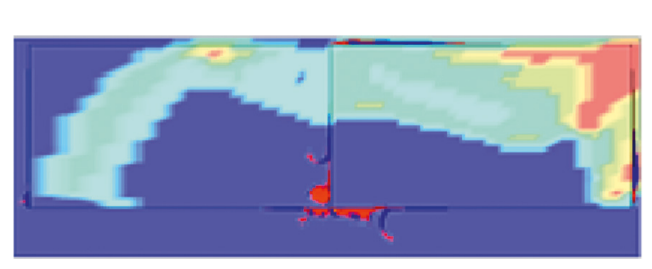

(b)

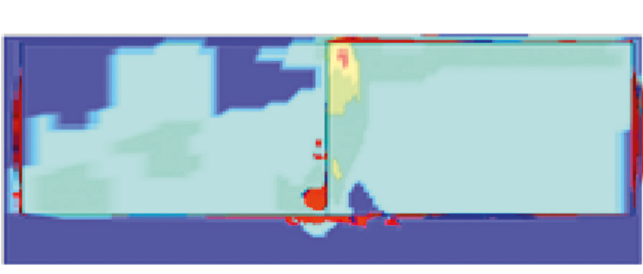

Fringe levels
$5.000 e+06$
$4.167 e+06$
$3.333 e+06-$
$2.500 e+06-$
$1.667 e+06-$
$8.333 e+04-$
$0.000 e+00$

(d)

FiguRE 11: Response process of explosion in position 4 (the axial longitudinal section, time unit: ms). (a) $t=0.7994$. (b) $t=2.7986$. (c) $t=5.1991$. (d) $t=9.7986$.

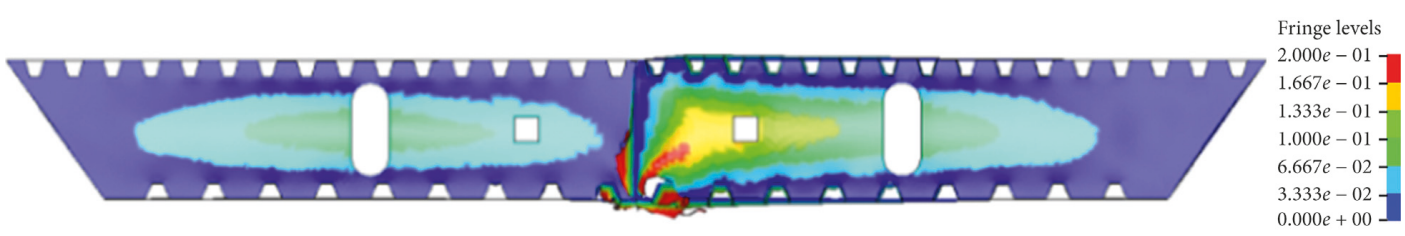

(a)

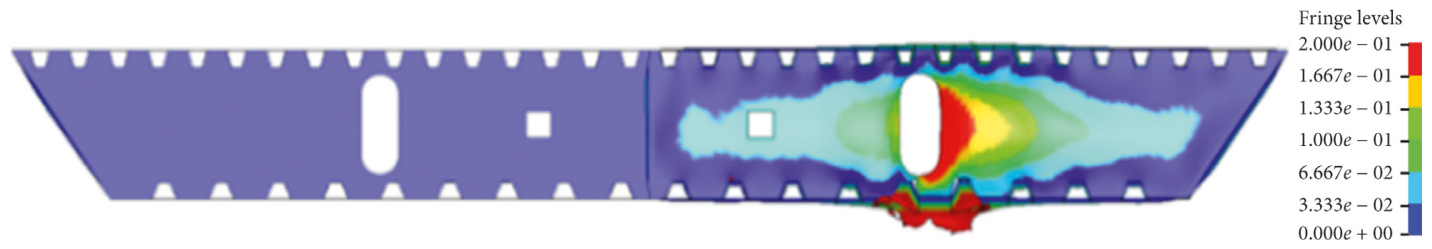

(b)

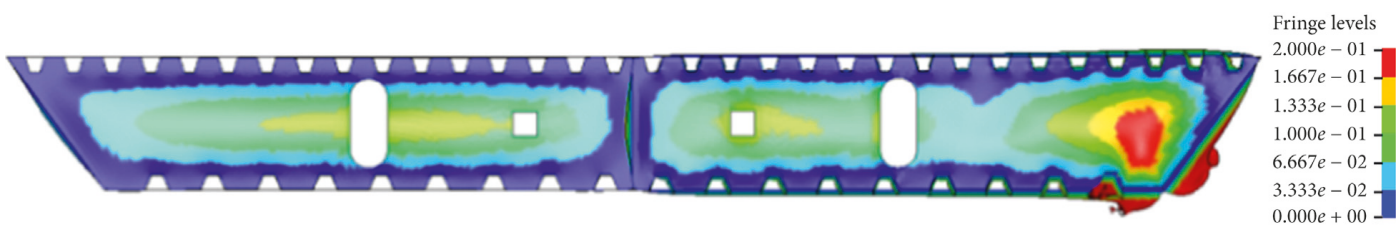

(c)

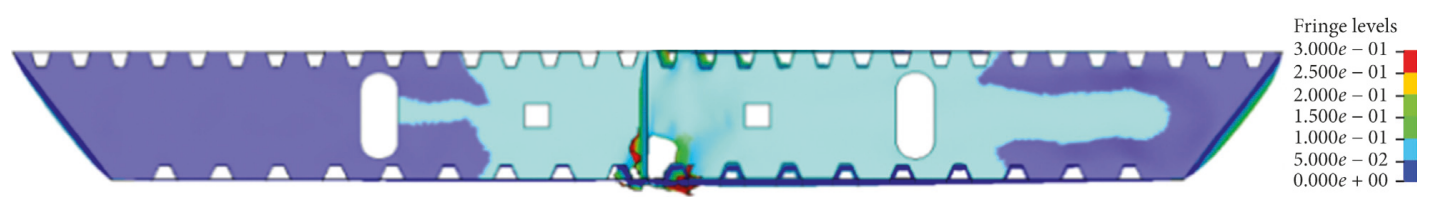

(d)

Figure 12: Fringe plot of the final displacement of the box girder (unit: m). (a) Position 1. (b) Position 2. (c) Position 3. (d) Position 4.

current study under four explosive positions: the plates close to the blast occurred crevasse and serve deformation (the bottom plate is cracked; nearby U-shaped ribs are destroyed), and the plate in the distance produced large plastic deformation caused by shock wave in which the pressure magnitude is much lower compared to that of the nearby blast wave.

The plates' failure mode can be divided into two kinds as follows: namely, inelastic large deformation and 


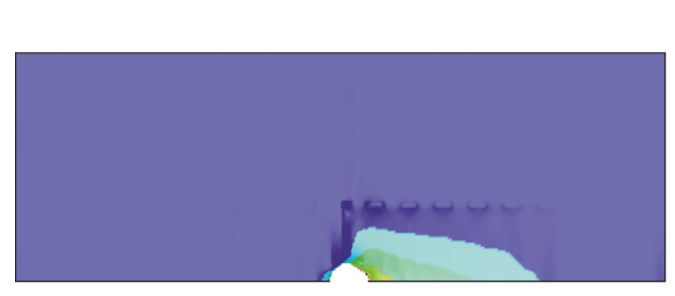

(a)

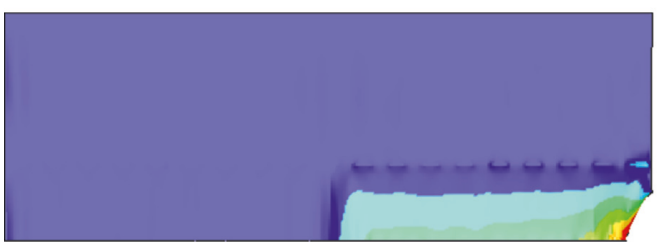

(c)

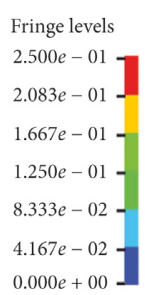

$0.000 e+00$
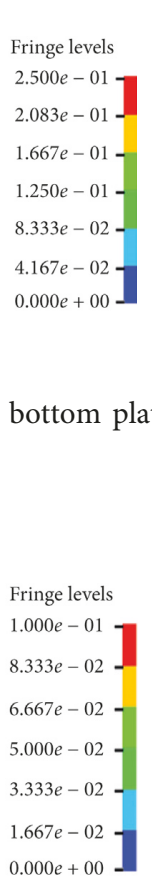

Figure 13: Fringe plot of the final displacement of the bottom plate (top view, unit: m). (a) Position 1. (b) Position 2. (c) Position 3. (d) Position 4. (a)
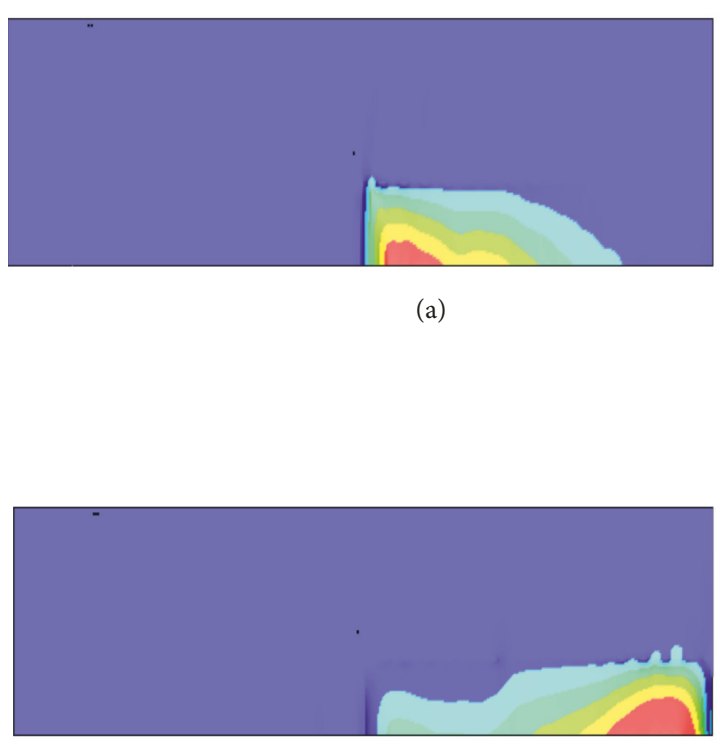

(c)

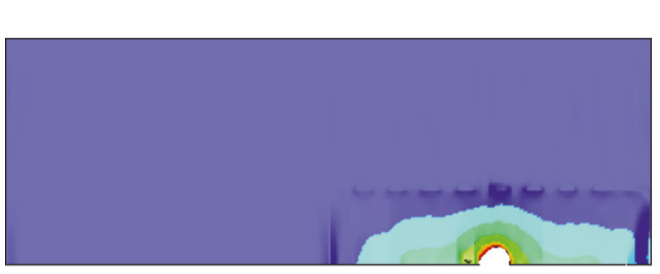

(b)

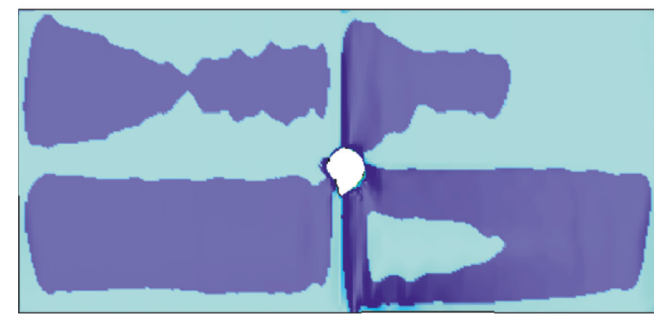

Fringe levels

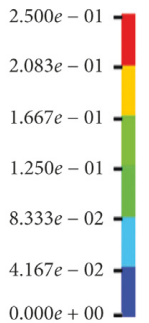

(d)

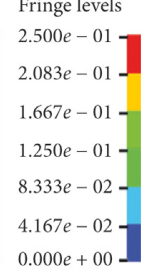

$0.000 e+00$ 


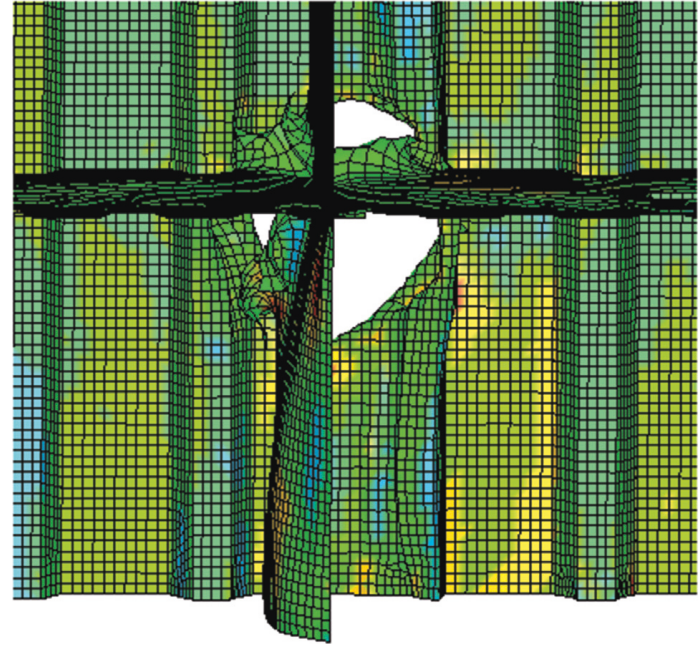

Figure 16: Final damage shape of explosion in position 4 (time unit: $\mathrm{ms})$.

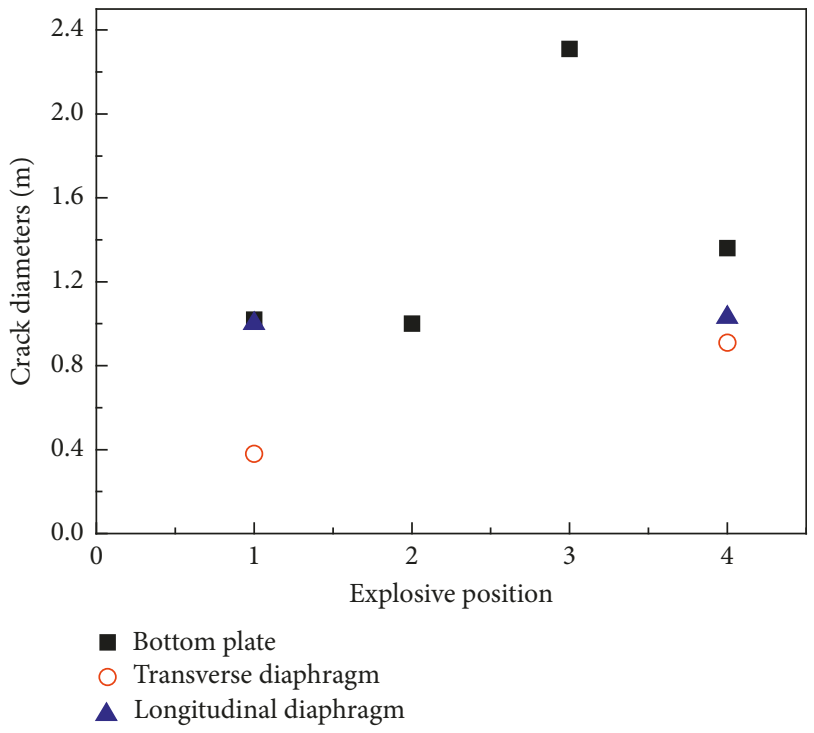

FIgURE 17: Crevasse diameter of plates in different explosive positions.

(1) To the bottom plate, $1 \mathrm{~m}$ diameter's breach is produced when blast starts off in positions 1,2 , and 4 , while in position 3 , a crack up to $2.31 \mathrm{~m}$ is emerged which may be caused by the split effect along the weld line between the inclined web and bottom plate. It can also be found out that the crevasse dimensions along the longitudinal direction are bigger than that along the transverse direction, which is because the U-shaped rib limited the development of crevasse along the transverse direction. A diameter range of 3 meters around positions 1 3 has experienced plastic deformation, while in position 4 , the range of plastic deformation is far less due to the constraint effect of longitudinal and transverse diaphragm.

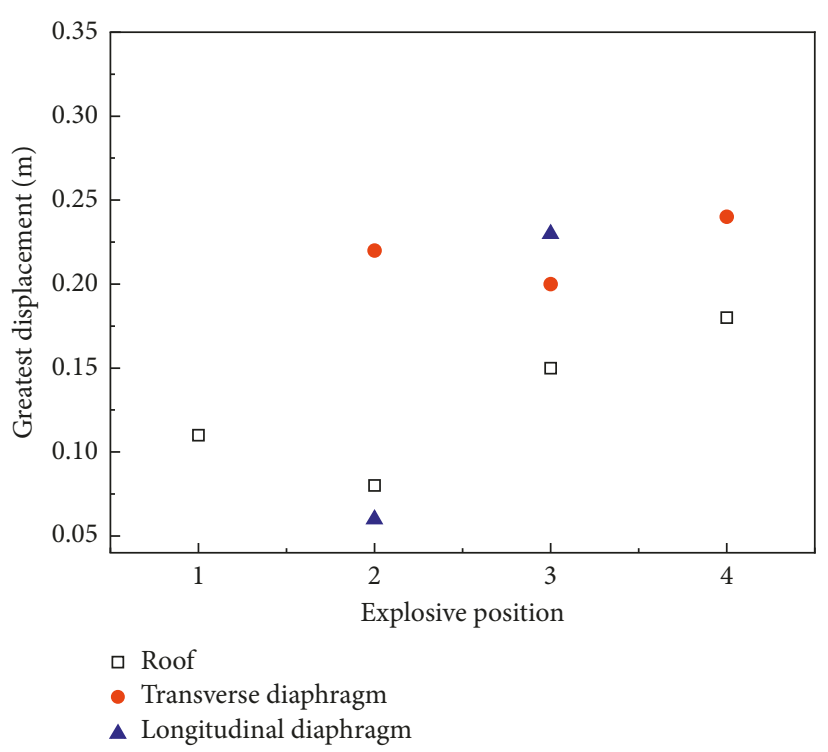

Figure 18: Greatest displacement of plates in different explosive positions.

(2) To the roof, great upward deflection is generated, especially in position 4 in which the shock wave is constrained and converged in the up-right corner of the box girder. And a range of 4.35-meter longitudinal plastic deformation is produced because of the same reason.

(3) To the diaphragm plate, the crevasse is only observed in position 1 and position 4; the crevasse reason in position 1 is that the shock wave was reflected and converged by the bottom plate and longitudinal diaphragm, in position 4 is the small blast standoff distance.

(4) To the longitudinal diaphragm, breaches only produce in close-in explosion (position 1 and position 4); the damage parameters of inclined web are not given here because only one crevasse up to $2.3 \mathrm{~m}$ produced in the right-inclined web (the same as the bottom plate).

To sum up, the explosive position has great influence on the damage degree. Explosion in position 4 creates the severest damage which may be caused by the three sides' constraint condition of explosive. And vice versa, in position 2 , the damage degree is relatively light; only the bottom plate produced a breach; the roof s displacement and plastic district range are minimums. To mitigate the damage degree and reduce the damage parameter of the steel box girder, some measures can be taken as follows: (1) improve the weld strength, to reduce split failure along the joint of plates; (2) increase the explosion-proof distance in the box corner, to prevent multichamber damage; and (3) set up transverse stiffener, to limit the development of the longitudinal crack.

5.3. Analysis of Explosive Mass. The damage features of different explosive masses exploded in position 2 are shown 


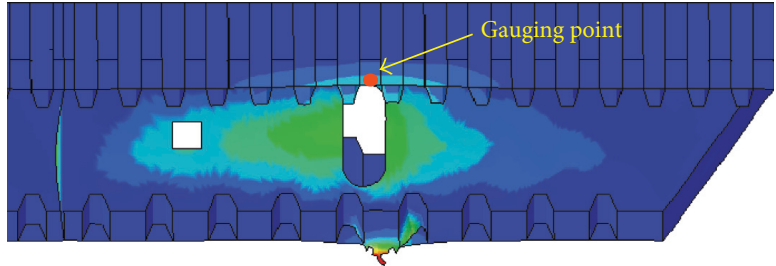

(a)

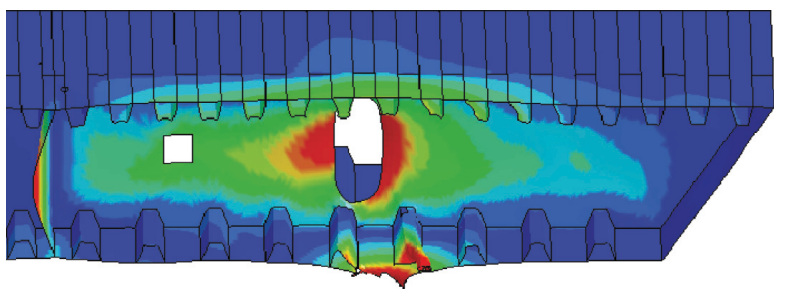

(c)

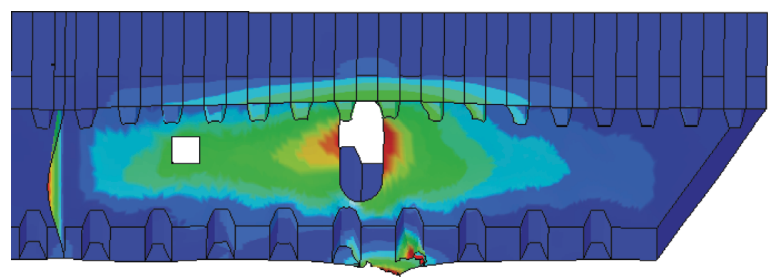

(b)

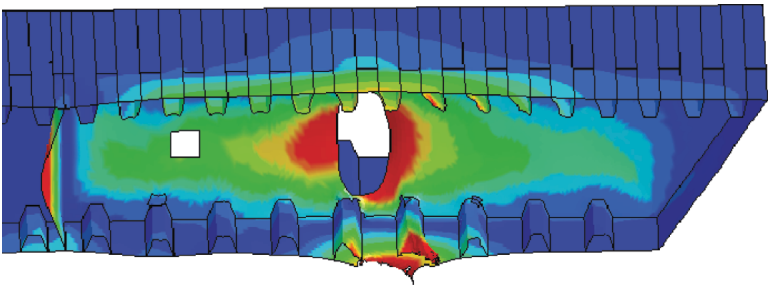

(d)

Figure 19: Damage features of different explosive masses in position 2. (a) $10 \mathrm{~kg}$ TNT. (b) $23 \mathrm{~kg}$ TNT. (c) $36 \mathrm{~kg}$ TNT. (d) $50 \mathrm{~kg}$ TNT.

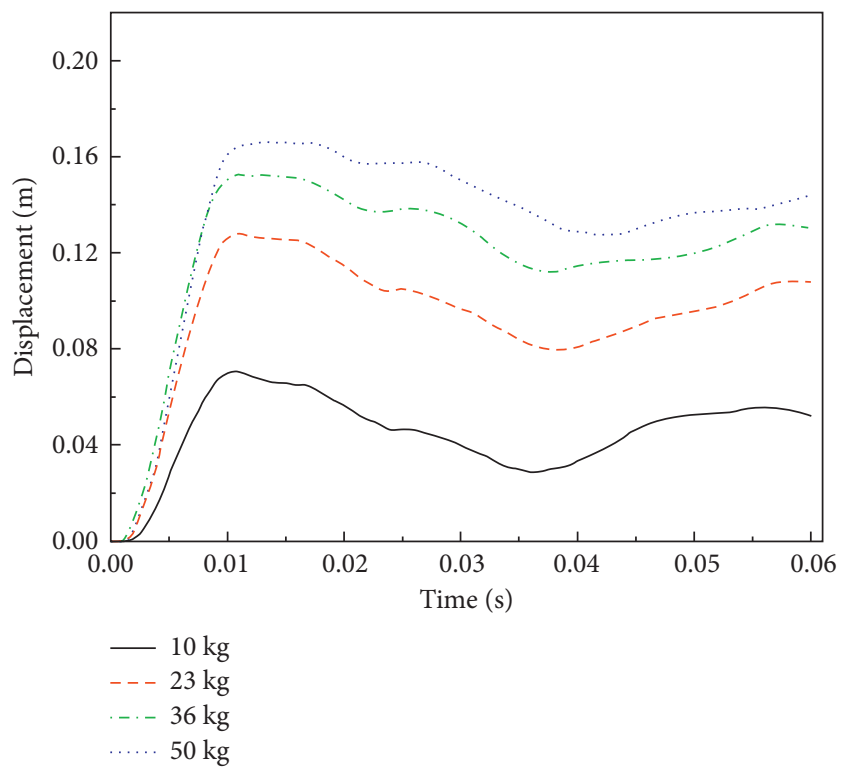

FIGURE 20: Displacement-time curves of the roof.

in Figure 19. With the increasing of TNT mass, the crack diameter in the bottom deck, the deformation degree of the roof, and the transverse and longitudinal diaphragm are all increased. Figure 20 shows the displacement-time curves of the gauging point in the roof (Figure 19(a)). The maximum deflections occur at about $t=0.01 \mathrm{~s}$ with the magnitudes of $0.07 \mathrm{~m}$ in $10 \mathrm{~kg}$ TNT case and $0.162 \mathrm{~m}$ in $50 \mathrm{~kg}$ TNT case. Figure 21 shows the crack diameter of the bottom plate of both transverse and longitudinal directions. The results show that the longitudinal crack is bigger than that of the transverse crack in all cases, and the longitudinal crack increases sharply with the TNT mounting up while the transverse crack increases gently. These phenomena result from the constrain effects of the longitudinal " $n$ "-shaped stiffener. In addition,

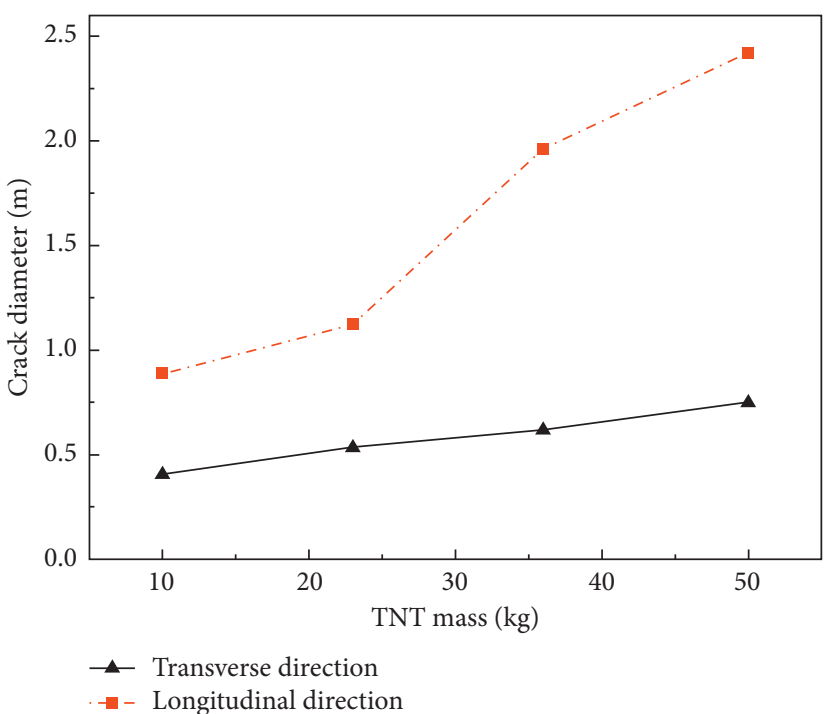

Figure 21: Crack diameter of the bottom plate.

due to the tearing that happens along the longitudinal stiffener, the longitudinal crack in $36 \mathrm{~kg}$ TNT case extremely increased comparing to $23 \mathrm{~kg}$ case. The results indicated that the one-way stiffener can restrict the damage to develop in the perpendicular direction of stiffener while increase the crack diameter along the stiffener direction. Hence, two-way orthogonally welded stiffeners should be designed to enhance the antiblast capability.

\section{Concluding Remarks}

Aiming at the problem of large span cable-supported steel bridges suffering the threat of terrorist blast attack, the dynamic response process and propagation of internal shock wave of the steel box girder under internal blast loading were investigated in the current research with nonlinear finite 
element software LS-DYNA and the fluid-solid coupling arithmetic method of ALE multimaterial formulations. The failure mode and the influence of blast position as well as explosive mass were discussed.

The results show that the response process of the steel box girder under internal blast loading is different from that of the external explosion for a multi-impact effect is observed which is caused by the reflection of the shock wave, and the second impact effect seems cannot be ignored. When the internal shock waves propagated to the weld area of two plates and the corner of box, they converged and will be intensified, and the enhanced shock wave has much bigger load effects.

The holistic failure mode of the girder is observed as local failure, and there are two failure modes for the steel box girder's components, large plastic deformation and rupture. Explosive position has strong effect on the box's destruction, for a multibox destruction will be caused if the explosion takes place at the juncture of two boxes. The constraint effects of the box also have great influence on the damage degree. With the increasing of TNT mass, the crack diameter in the bottom deck, the deformation degree of the roof, and the transverse and longitudinal diaphragm are all increased. The longitudinal stiffeners restrict the damage to develop in the transverse direction while increase the crack diameter along the stiffener direction.

Some measures can be taken to enhance the antiblast capability of a steel box girder by improving the weld strength, increasing the explosion-proof distance in the box corner, setting up two-way orthogonally welded stiffeners, and increasing the venting area to decrease the effect of confined explosion. Numerical results presented in the current study may help structure or bridge engineers to determine appropriate protection measures for bridges and structures against possible explosion loads.

\section{Conflicts of Interest}

The authors declare that they have no conflicts of interest.

\section{References}

[1] The Blue Ribbon Panel on Bridge and Tunnel Security, Recommendations for Bridge and Tunnel Security, FHWA, Washington, DC, USA, 2003.

[2] Transport Canada, "Terrorist Attack Methodology and Tactics Against Bridges and Tunnels: January 2002-December 2008," Intelligence Report, IR\#92-2009, 2009.

[3] H. Lin and A. R. Chen, "Study of performance-based antiterrorism design for bridges," Journal of Tongji University (Natural Science), vol. 37, no. 8, pp. 999-1002, 2009.

[4] T. Krauthammer, A. Assadi-Lamouki, and H. M. Shanaa, "Analysis of impulsively loaded reinforced concrete structural elements," Computers \& Structures, vol. 48, no. 5, pp. 851-860, 1993.

[5] H. Y. Low and H. Hao, "Reliability analysis of direct shear and flexural failure modes of RC slabs under explosive loading," Engineering Structures, vol. 24, no. 2, pp. 189-198, 2002.

[6] T. Ngo, P. Mendis, A. Gupta, and J. Ramsay, Blast Loading and Blast Effects on Structure-An Review, Electronic Journal of Structural Engineering Special Issue, 2007.
[7] D. G. Winget, K. A. Marchand, and E. B. Williamson, "Analysis and design of critical bridges subjected to blast loads," ASCE Journal of Structural Engineering, vol. 131, no. 8, pp. 1243-1255, 2005.

[8] S. Fujikura, M. Bruneau, and D. Lopez-Garcia, "Experimental investigation of muliti-hazard resistant bridge piers having concrete-filled steel tube under blast loading," Journal of Bridge Engineering, vol. 13, no. 6, pp. 586-594, 2008.

[9] X. Q. Zhou, V. A. Kuznetsov, H. Hao, and A. Waschl, "Numerical prediction of concrete slab response to blast loading," International Journal of Impact Engineering, vol. 35, no. 10, pp. 186-200, 2008.

[10] W. Riedel, C. Mayrhofer, K. Thoma, and A. Stolz, "Engineering and numerical tools for explosion protection of reinforced concrete," International Journal of Protective Structures, vol. 1, no. 1, pp. 85-101, 2010.

[11] R. B. Deng, X. L. Jin, X. D. Chen, and Z. Li, "Numerical simulation for the damage effect of bridge subjected to blast wave," Journal of Shanghai Jiaotong University, vol. 42, no. 11, pp. 1927-1930, 2008.

[12] J. Son, "Performance of cable supported bridge decks subjected to blast loads," Ph.D. thesis, University of California, Berkeley, CA, USA, 2008.

[13] J. Son and H. J. Lee, "Performance of cable-stayed bridge pylons subjected to blast loading," Engineering Structures, vol. 33, no. 4, pp. 1133-1148, 2011.

[14] E. K. C. Tang and H. Hao, "Numerical simulation of a cablestayed bridge response to blast loads, Part I: model development and response calculations," Engineering Structures, vol. 32, no. 10, pp. 3180-3192, 2010.

[15] H. Hao and E. K. C. Tang, "Numerical simulation of a cablestayed bridge response to blast loads, Part II: damage prediction and FRP strengthening," Engineering Structures, vol. 32, no. 10, pp. 3193-3205, 2010.

[16] Z. G. Jiang, X. M. Zhu, B. Yan, and S. J. Yao, "Numerical simulation on local failure of steel box girders under blast loading," Journal of Vibration and Shock, vol. 32, no. 13, pp. 159-164, 2013.

[17] S. J. Yao, F. Y. Lu, Z. G. Jiang et al., "Research on the shock wave and failure modes of steel box subjected to internal blast loading," Acta Armamentarii, vol. 34, pp. 314-320, 2013.

[18] W. E. Baker, Explosion Hazards and Evaluation, New York Elsevier Publishing Company, New York, NY, USA, 1983.

[19] Y. Lu and K. Xu, "Prediction of debris bunch velocity of vented concrete structure under internal blast," International Journal of Impact Engineering, vol. 34, no. 11, pp. 1753-1767, 2007.

[20] S. J. Yao, D. Zhan, X. G. Chen, F. Y. Lu, and P. D. Zhao, "A combined experimental and numerical investigation on the scaling laws for steel box structures subjected to internal blast loading," International Journal of Impact Engineering, vol. 102, pp. 36-46, 2017.

[21] M. S. Gadala and J. Wang, "ALE formulation and its application in solid mechanics," Computer Methods in Applied Mechanics and Engineering, vol. 167, no. 1-2, pp. 33-35, 1998.

[22] N. Aquelet, M. Souli, and L. Olovsson, "Euler-Lagrange coupling with damping effects: application to slamming problems," Computer Methods in Applied Mechanics and Engineering, vol. 195, no. 1-3, pp. 110-132, 2006.

[23] M. Souli, N. Aquelet, E. Al-Bahkali, and M. Moatamedi, "A mapping method for shock waves using ALE formulation," Computer Modeling in Engineering and Sciences (CMES), vol. 91, no. 2, pp. 119-133, 2013.

[24] A. Alia and M. Souli, "High explosive simulation using multimaterial formulations," Applied Thermal Engineering, vol. 26, no. 10, pp. 1032-1042, 2006. 
[25] LSTC, LS-DYNA Keyword User's Manual, Livermore Software Technology Corporation, Livermore, CA, USA, 2007.

[26] G. R. Johnson and W. H. Cook, "A constitutive model and data for metals subjected to large strains, high strain rate and high temperatures," in Proceedings of the 7th International Symposium on Ballistics, The Hugue, Netherlands, 1983.

[27] S. Dey, T. Børvik, O. S. Hopperstad, and M. Langseth, "On the influence of constitutive relation in projectile impact of steel plates," International Journal of Impact Engineering, vol. 34, no. 3, pp. 464-486, 2007.

[28] T. S. Huang, "The introduction of the steel box girder of Dadao-Bridge," Bridges Abroad, vol. 2, pp. 93-101, 1994. 


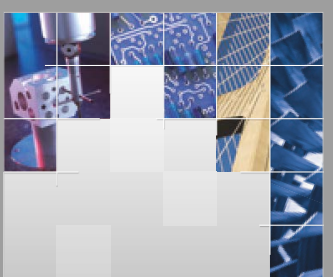

\section{Enfincering}
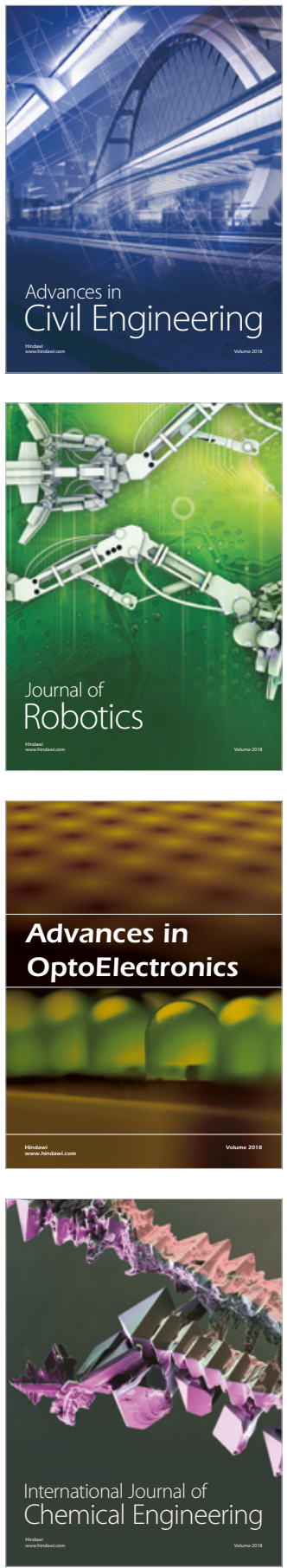

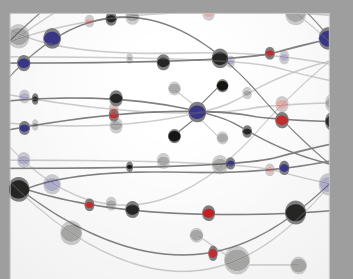

\section{Rotating \\ Machinery}

The Scientific World Journal

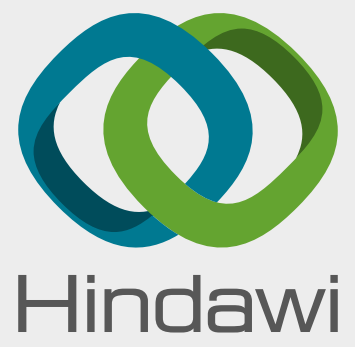

Submit your manuscripts at

www.hindawi.com
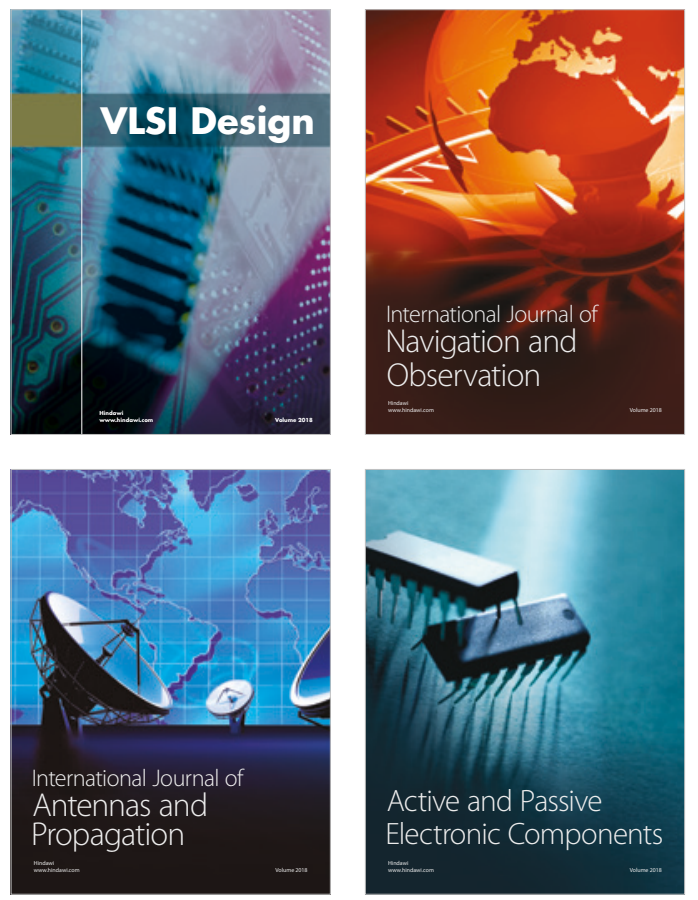
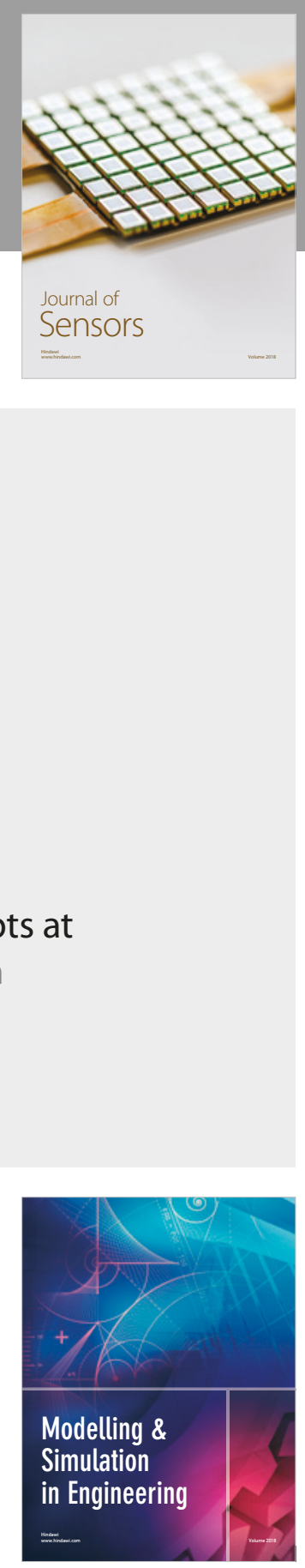

\section{Advances \\ Multimedia}
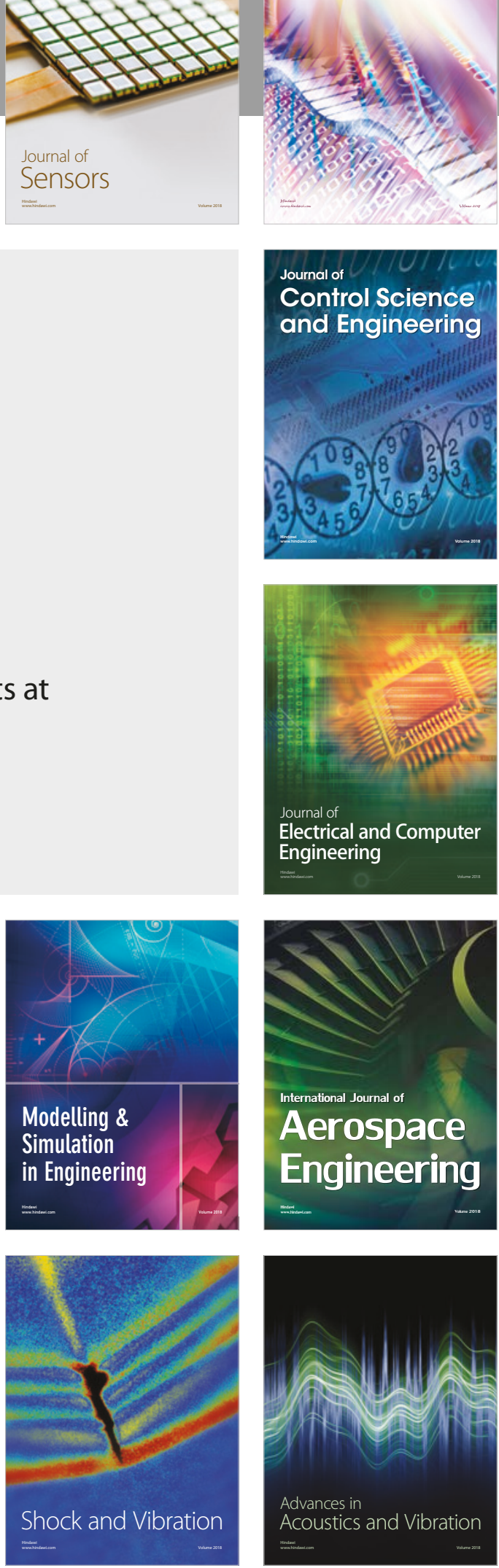